\title{
NEODIPLOSTOMUM BANGHAMI, A NEW DIPLOSTOMATID STRIGEOIDEAN TREMATODE FROM AN EAGLE
}

FAYE WHITE PENROID 


\section{NEODIPLOSTOMUM BANGHAMI, A NEW DIPLOSTOMATID STRIGEOIDEAN TREMATODE FROM AN EAGLE*}

\section{Faye Weite Penrod}

Ten worms mounted in toto on two microscope slides were used in this study. Dr. Ralph V. Bangham of Wooster College (Ohio) presented the

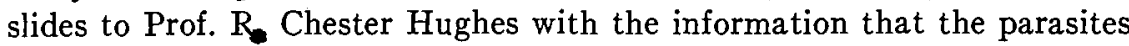
were from an immature bald eagle, Baliaeetus leucocephalus (Linné, 1766), which bad been taken in northern Wayne County, Ohio, in the fall of 1945. Data with the specimens indicate that they were fixed in seven per cent formalin, stained in Delafield's hematoxylin, and mounted in clarite. As far as practicable all ten worms were used in making the measurements recorded below.

\section{Neodiplostomum banghami, n. sp.}

(Figure 1)

Description. Body 2.09 (1.82-2.51) $\mathrm{mm}$ in total length; distinctly subdivided by a constriction into fore and hind parts, being $0.43(0.36-0.52)$ $\mathrm{mm}$ wide at constriction. Forebody $1.3(1.05-1.61) \times 0.56(0.49-0.63) \mathrm{mm}$; 1.65 (1.37-1.89) times length of hindbody; thin, leaflike, and scoop-shaped; being deeply concave posteriorly with lateral edges curled ventrad and continuous with each other behind holdfast organ. Hindbody 0.79 (0.66$0.94) \times 0.61(0.52-0.71) \mathrm{mm}$, ovoidal to subcylindrical, widest at midlength. Oral sucker ventrosubterminal, spheroidal, $48(46-53) \times 50(46-$ 59) $\mu$. Acetabulum spheroidal to transversely subelongate, $49(45-53) \times 53$ (46-66) $\mu$, slightly larger than oral sucker, situated at about one-third length of forebody from anterior end. Holdfast organ 496 (341-633) $\times 170$ (164-184) $\mu$, very narrowly ellipsoidal, generally entirely though barely behind middle of forebody. Distance between rear surface of acetabulum and front end of holdfast organ $128(112-152) \mu$. Neither holdfast glands nor general cuticular spination were observed. Excretory pore dorsosubterminal. Common genital pore transversely elongate, located on dorsal surface slightly in front of excretory pore and at 112-144 from posterior extremity.

Pharynx $56(53-66) \times 46(39-66) \mu$, usually a little longer and a little more slender than oral sucker. Prepharynx virtually wanting. Oesophagus very short, 39 (33-53) $\mu$. Caeca, very slender and narrowly divergent, extend posteriad dorsal to lateral surfaces of holdfast organ and terminate in slight enlargements just anterodorsal to genital atrium.

Testes occupy nearly entire width and approximately central half or three-fifths of hindbody; subequal in size, the anterior being usually a little

* Contribution No. 125 from the Department of Zoology, Oklahoma Agricultural and Mechanical College; prepared under the direction of R, Chester Hughes. 


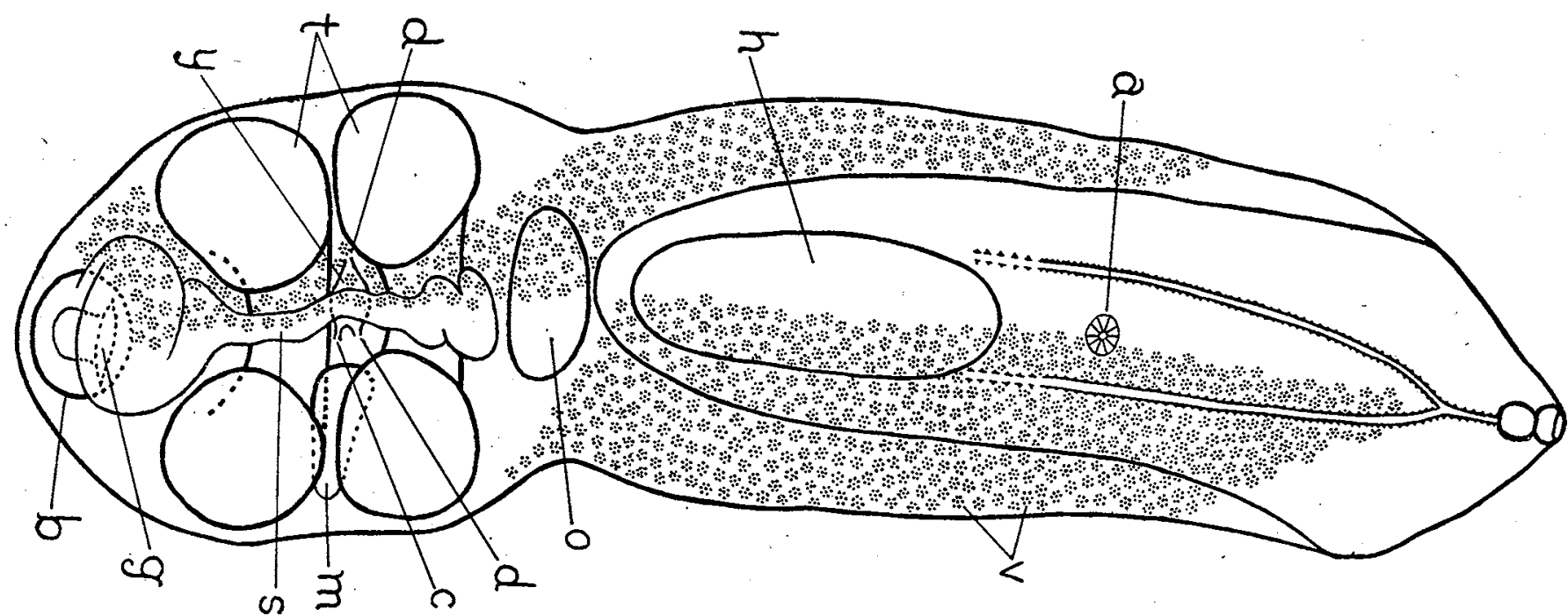

FIG. 1. Neodiplostomim banghami n. sp., composite study, ventral view. The more ventrally distributed vitellaria are shown in the left side of the figure; the dorsal ones in the right. Abbreviations: $a$, acetabulum; $b$, bursa copulatrix; $c$ common vitellaria are shown in the left side of $g$, genital pore; $h$, holdfast organ; $m$, Mehlis' gland; $o$, ovary; $s$, vas deferens; $t$, testes; $v$, vitellaria; $y$, yolk reservoir. 
the larger; of irregular form, each being somewhat dumbbell-shaped with its left lobe a little the larger and with its long axis bent into a U. Anterior testis vertically oriented with its convex side directed dorsad; its transverse diameter 571 (505-643) $\mu$; longitudinal diameter of its left lobe $220 \mu$, that of its right lobe $193 \mu$. Posterior testis obliquely placed with convex side directed dorsosubanteriad; 513 (433-577) $\mu$ in transverse diameter; length of left lobe $203 \mu$, that of right lobe $197 \mu$. Minimum longitudinal diameter of isthmus of either testis about $100 \mu$. In one specimen the anterior testis was apparently lacking although there was vacant space enough for its occurrence; in another worm the posterior testis was markedly undersized-this testis was not included in the measurements lisi ed above. Vasa efferentia not observed. Vas deferens mainly a large and slightly convoluted median canal lying beneath and between lateral lobes of testes; slightly enlarged anterior to testes as a "seminal reservoir"; more conspicuously enlarged and coiled behind testes as a seminal vesicle. Bursa copulatrix muscular, usually transversely elongate, $159(118-177) \times 195(164-262) \mu$; not everted in any of our specimens. Genital cone apparently wanting.

Vitelline follicles small, numerous, and widely distributed in paired lateral fields which, however, are contiguous with each other along most of their lengths. Vitelline fields of greater thickness than a single layer, follicles being visible both above and beneath the intestinal crura in anterior segment. In forebody vitelline fields extend forward medially almost to bifurcation of oesophagus; laterad their front boundaries recede so that near margins of body the follicles may extend only to, or a little farther forward thán, level of acetabulum. At juncture of the two body regions the fields encircle body. Shortly behind constriction the distribution recedes from dorsal area and fields soon become a single narrow median band which widens slightly at intertesticular level and enlarges again behind rear testis; fields separate slightly at level of bursa copulatrix. Paired vitelline ducts arise from lateral margins of intertesticular expansion in median band of vitellaria and curve dorsad soon to connect with a sizable submedian yolk reservoir from which a common vitelline duct extends laterad (usually sinistrad) toward Mehlis' gland.

Ovary far forward in hindbody and submedian in position, narrowly and transversely elongate, $106(98-144) \times 249(216-275) \mu$. Oviduct not traced. Mehlis' gland at middepth of body, intertesticular, and far to one side being usually sinistral but sometimes dextral; transversely elongate; about $55 \times 137 \mu$. Uterus traced with difficulty; judging from distribution of eggs it extends foward from Mehlis' gland dorşal to left lobe of anterior testis; has a transverse section, often dilated and sperm-filled, contiguous with posterior surface of ovary; makes an anteriad loop which lies dorsal to, and reaches a little in front of, ovary; then runs almost directly posteriad in median plane dorsal to testes to genital atrium. Eggs $87-123 \times 68-81 \mu$; number in utero, 0-27. 
Host. Haliqeetus leucocephalus (Linné, 1766).

Locality. Northern Wayne County, Ohio.

Cotype Material. Ten specimens (two of them badly damaged as a result of cover-glass pressure) mounted in toto on two microscope slides; No. 37003 in the Helminthological Collection of the United States National Museum.

\section{Discusston}

Dubois (1944) listed thirty-one species of Neodiplostomum; apparently overlooked were two forms described by Vidyarthi (1938) and one by Lal (1939). Thus with the new form, Neodiplostomum Railliet 1919 now comprises thirty-five recognized species known in adult form; this number is exclusive of several species which are known only as larvae or have been provisionally listed in the genus as species inquirendae (Dubois, 1938; Bhalerao, 1942). The recognized species all parasitize avian definitive hosts. The majority of the hosts are Falconiformes or Strigiformes but the orders Ciconiiformes, Coarciiformes, Cuculiformes, Passeriformes, and Piciformes are also represented.

Species of Neodiplostomum have been found in each of six continents and in the Philippine Islands. Only two species have been previously reported from North America: $N$. cochleare listed (Dubois, 1938) from Bubo virginianus (Gmelin) and Nyctea nyctea (L.) in Minnesota and N. paraspathula described (Noble, 1936) from Archibuteo ferrugineus (Licht) in California and reported (Caballero, 1944) from Aquila chrysaetos in Mexico.

The new species was studied in comparison with descriptions of all of the previously known adult forms. The comprehensive monograph by Dubois (1938) is the source of information used for the older species; original descriptions (Vidyarthi, 1938; Lal, 1939; Yamaguti, 1939) were used for the newer ones. The previously known species of Neodiplostomum which most nearly resemble $N$. banghami n. sp. are listed below together with tabulations of the principal differences which severally distinguish them from the new form.

$N$. cochleare (Krause, 1914) La Rue, 1926 (from owls in Egypt and Minnesota) has a larger size; the forebody wider than the hindbody, longer relative to the holdfast organ, and with its edges not always curved ventrad; the holdfast organ more nearly circular; the vitelline follicles more widely distributed in the hindbody; the testes of equal diameter and causing the sides of the body to bulge; a larger bursa copulatrix; and more narrowly ellipsoidal eggs.

$N$. conicum Dubois, 1937 (from owls and hawks in Brazil) has a smaller size, a more conical hindbody, the pharynx shorter than the oral sucker, the ventral sucker larger and nearer to the more broadly ellipsoidal holdfast organ, the vitellaria more widely distributed in the forebody but extending not so far posteriad in the hindbody, the ovary in the forebody, and the testes farther anteriad. 
N. palumbarii Dubois, 1937 (from a European hawk) has the forebody of different shape, wider than the hindbody, longer relative to the lengths of both the hindbody and the holdfast organ, and with more pronounced ventrad reflection of its lateral edges; the pharynx and oral sucker smaller and more nearly equal in size; the acetabulum farther from the holdfast organ; the testes considerably smaller and occupying less of the body width; and a genital cone.

$N$. sarcorhamphi Dubois, 1937 (from a South American condor) has the forebody wider than the hindbody, wider than in the new species, and with its lateral edges less recurved; the holdfast organ much wider and more broadly ellipsoidal; the vitelline follicles extending farther forward in the forebody; the ovary larger and situated more anteriad; a more elongate hindbody; a genital cone; a more nearly terminal genital pore; and more elongate eggs.

\section{Literature Cited}

Bhalerao, G. D. 1942. On Strigeida (Trematoda) from India. Rec. Indian Mus. 44(2): 210 212.

Caballero y C., E. 1944. Neodiplostomum paraspathula Noble, 1936 (Trematoda: Diplostomidae) en un aguila de México. An. Inst. Biol., Univ. México 15(1): 47-52.

Dubois, G. 1938. Monographie des Strigeida (Tremadota). Mém. Soc. Neuchatel. Sc. Nat. 6: $1-535$.

1944. A propos de la spécificité parasitaire des Strigeida. Bull. Soc. Neuchatel. Sc. Nat. 69: 5-103.

Lal, M. B. 1939. Studies in helminthology. Trematode parasites of birds. Proc. Indian Acad: Sc., Sec. B 10(2): 111-200.

Noble, A. E. 1936. New avian trematodes of the genus Neodiplostomum. Jour. Parasitol..22(3): 247-250.

Vidyarthi, R. D. 1938. New avian trematodes (family Diplostomidae) from Indian birds. Proc. Nat. Acad: Sci., India 8(3): 76-84.

Yamaguti, S. 1939. Studies on the helminth fauna of Japan. Part 25. Trematodes of birds, IV. Japan. Jour. Zool. 8(2): 129-210. 